\title{
ENTREVISTA
}

do https://doi.org/10.22481/praxisedu.v16i40.6898

\section{CIDADES PARA E DAS CRIANÇAS: UMA CONVERSA NO TALLER ABIERTO EM PONTEVEDRA, ESPANHA ${ }^{1}$}

\author{
CITIES FOR AND CHILDREN: A CONVERSATION AT TALLER ABIERTO IN \\ PONTEVEDRA, SPAIN
}

\section{CIUDADES PARA Y LOS NIÑOS: UNA CONVERSACIÓN EN TALLER ABIERTO EN PONTEVEDRA, ESPAÑA}

\author{
Marcia Aparecida Gobbi ${ }^{2}$ \\ Universidade de São Paulo - Brasil
}

\begin{abstract}
Resumo: Em que as experiências nas cidades chamadas por Francesco Tonucci de "cidades das crianças" podem contribuir para nossas vidas como moradoras de centros urbanos? Os pontos de vista de meninas e de meninos são considerados quando são feitas mudanças de qualquer ordem nas cidades? Essas e outras perguntas orientaram uma conversa-entrevista realizada na Associación Taller Abierto, situado na cidade de Pontevedra, Espanha, em julho de 2019. A partir de um roteiro semiestruturado o diálogo ocorreu de forma livre em que todas as envolvidas transcorreram sobre o tema instigando a pensar cidades com crianças. O objetivo foi conhecer uma destas cidades aproximando-se de suas práticas e cotidiano, bem como, daquelas e daqueles que contribuem para a materialização de propostas em que a centralidade das crianças é compreendida como tônica da cidade.
\end{abstract}

Palavras chave: Cidades das crianças. Pontevedra. Francesco Tonucci.

Resumen: : ¿En qué ciudades las experiencias llamadas "ciudades infantiles" pueden contribuir a nuestras vidas como habitantes del centro urbano? ¿Se tienen en cuenta las opiniones de niñas y niños cuando se realizan cambios de pedido en las ciudades? Estas y otras preguntas guiaron una conversación de entrevista celebrada en la Associación Abierto Taller, ubicada en la ciudad de Pontevedra, España, en julio de 2019. A partir de un guión semiestructurado, el diálogo fue libremente en el que todos los involucrados pasaron por el tema instigando a pensar en las ciudades con niños. El objetivo era conocer una de estas ciudades acercándose a sus prácticas y a su vida cotidiana, así como a las y aquellas que contribuyen a la materialización de propuestas en las que la centralidad de los niños se entiende como la nota clave de la ciudad.

Palabras clave: ciudad de los niños. Infancia y ciudad. Francesco Tonucci

Abstract: How can experiences in cities called "children's cities" contribute to our lives as urban centre dwellers? Are the views of girls and boys considered when changes of any order are made in cities? These and other questions guided an interview conversation held at the Associación Taller Abierto, located in the city of Pontevedra, Spain, in July 2019. From a semi-structured script, the dialogue went freely in which all

\footnotetext{
${ }^{1}$ Tratou-se aqui de uma tradução livre da conversa/entrevista em que se procurou guardar todo seu conteúdo e ideias fundamentais. Revisão técnica: Cleriston Izidro dos Anjos, Juliana Diamente Pito e Paula Martins Vicente.

${ }^{2}$ Entrevistadora e tradutora da entrevista, realizada originalmente em espanhol.
} 
those involved went through the theme instigating to think about cities with children. The objective was to know one of these cities approaching their practices and daily life, as well as those and those that contribute to the materialization of proposals in which the centrality of children is understood as the keynote of the city.

Palabras clave: children's city. Childhood and city. Francesco Tonucci.

\section{Introdução}

Considerar as crianças como paradigmas para pensar as cidades é uma das grandes defesas e lutas do renomado pedagogo Francesco Tonucci. Derivam disto pesquisas de tantos e tantas pesquisadores e pesquisadoras que, pelo mundo, têm investigado cidade e infância, como grande temática, e seus inúmeros desdobramentos. Além de investigações de cunho acadêmico e educacional, as propostas de Tonucci, fundamentais e inquietantes, foram tomadas como princípio em várias cidades, sendo que na América do Sul temos a cidade de Rosário e na Espanha, Pontevedra, cuja proposta de mudança está sendo construída desde 2000. Trata-se de uma ação que exige empenho político e escuta atenta e respeitosa daquilo que as crianças, desde bebês, manifestam de diferentes modos, daquilo ${ }^{3}$ que nos dizem, do que nos solicitam e provocam. Essa postura, bastante desafiadora, exige mudança de paradigmas. Sendo que refletir sobre os modos excludentes e adultocentrados com os quais agimos constitui-se como ponto fulcral de possíveis mudanças, sobretudo, relacionadas às políticas públicas urbanas e educacionais.

Durante breve pesquisa sobre as "cidades das crianças" e suas propostas para e com elas, em julho de 2019, participei de uma boa e entusiasmada conversa com Ana Barreiro e África Martinez, arquitetas responsáveis pela Associación Taller Abierto, situado em Pontevedra e que consiste num coletivo de mulheres arquitetas que pensam, com as crianças, propostas para a cidade. Alguns destes projetos que envolvem a comunidade escolar e o município, tem se apresentado como fundamentais para a constituição desta cidade para e das crianças e sublinham a existência de práticas democráticas em que o diálogo entre todos se constitui como o enlace da vida citadina. Consideramos que elas nos apresentam bons elementos para pensar sobre cidades, infância e a centralidade das crianças e refletir sobre nós, no Brasil e nossas especificidades, nossas crianças e suas formas de estar no mundo, como crianças brasileiras. Mudanças estruturais são necessárias e este é apenas um convite para pensar sobre elas. O ponto de vista das crianças é compreendido como fundamental para

\footnotetext{
${ }^{3}$ Doravante Ana Barreiro e África Martinez serão chamadas apenas pelo primeiro nome.
} 
promover transformações que acolham a todos e a todas, como consideram Ana e África ao longo de nossa conversa.

O encontro aconteceu no mês de julho de 2019, como conversa livre, agendada, o que resultou em falas com caráter dialogado. Ela foi regada a muitas imagens e livros em que os projetos estavam retratados, algumas das quais, compartilho os links em nota ${ }^{4}$. São pistas a serem seguidas para que o diálogo continue e se reproduza em críticas e outras reflexões. Embora a conversa tenha sido feita em espanhol, ao apresentar a transcrição intentei manter o modo de referir-se a alguns projetos e construção da narrativa presente ao longo do encontro que se deu num quente dia de verão. Ao longo de algumas horas foram abordados os projetos realizados e outros por vir, buscou-se colocar links que aproximem o leitor ou a leitora do conteúdo abordado ao longo da conversa. Faço uso de parênteses quando julgar necessário dar algumas explicações sobre o conteúdo e o andamento deste encontro.

\section{Uma conversa sobre cidades das e para as crianças}

Nos reunimos numa ampla sala de reuniões, situada na região central da cidade. Ana e África, pautadas no fato de eu ser brasileira, buscam um livro como mote para o início da conversa sobre projetos realizados conjuntamente com escolas de educação infantil e de ensino fundamental. O tom da conversa centra-se numa pergunta: e se as cidades fossem projetadas por crianças? E se os projetos e políticas públicas considerassem as crianças? O que sabemos sobre cidades que consideram o ponto de vista das crianças como elemento para impulsionar políticas? Com tantas questões mostram-me um projeto, publicado e discutido no congresso LUDANTIA, I Bienal Internacional de Educação e Arquitetura para Infância e Juventude ${ }^{5}$, que aconteceu em Pontevedra, em maio de 2017. Não à toa, elas buscam pelo livro e o folheiam, para além de mostrarem seus projetos constantes entre as páginas, comentam sobre um projeto premiado e publicado no livro de mesmo título.

Ana: Veja (mostrando-me o livro), tem um projeto em São Paulo e que consta aqui, no livro, com fotos, é um projeto com casa na árvore.

\footnotetext{
${ }^{4}$ Com a intenção de que também caminhem pela cidade e alguns de seus projetos informo alguns dos links mencionados ao longo da conversa, são eles: Link do LUDANTIA - Congresso mencionado inicialmente https://ludantia.wixsite.com/bienal-internacional/publicaciones; Link do Taller Abierto http://tallerabierto.info/ ${ }^{5}$ Ludantia é uma associação estatal que reúne arquitetos e educadores, com grupo de pessoas e coletivos para discutir e consolidar propostas voltadas a questões concernentes à crianças, juventudes e cidades. O livro mencionado refere-se ao catálogo da I Bienal realizada pela associação e outros grupos interessados na temática.
} 
Marcia: No Brasil, qual?

Ana: Dona Leopoldina, um projeto com uma grande árvore. Você conhece?

Marcia: EMEI Dona Leopoldina ${ }^{6}$ ? Sim, muito!

Partimos de uma feliz coincidência e admiração comum ao projeto brasileiro e paulistano e seguimos com a conversa, cujo tom foram os projetos já encaminhados e outros por fazer. A grande questão é a relação entre crianças, escolas e seus desejos e necessidades e o poder público como fundamental para se construir uma cidade a partir do ponto de vista de meninas e de meninos.

Ana: Nós fizemos algo aqui parecido. Quero dizer, estamos tentando usar a cidade para explicá-la e a tantas coisas aqui existentes para as crianças. Entendemos nosso projeto, em que as crianças discutiam e tentavam compreender a cidade, dentro e fora da escola, como um momento em que levávamos a escola para a cidade e levávamos a cidade para a escola. Essa relação não pode deixar de acontecer, tem que ser provocada.

Vamos começar a falar desse projeto que você conhece, estamos aqui perto do Colégio de la Transformación de Plaza, fica bem aqui ao lado. E daqui começamos um de nossos projetos, que você sabe e já comentou e que a trouxe aqui (referiam-se ao projeto iniciado em 2016 e que havia chamado minha atenção tempos atrás ${ }^{7}$ ). Era tudo muito compartimentado e o que fizemos foi explicar às crianças algo muito básico, uma introdução à arquitetura. Começamos com perguntas: Qual era o trabalho a ser feito na escola? Quais eram suas ferramentas que poderíamos usar? Estávamos falando de escala. Estávamos falando de território. Estávamos falando de paisagem. Essa escola tinha uma peculiaridade: não tinha um playground. As crianças não tinham espaço para sair, tinham um espaço interno, completamente fechado e lá fora, a rua. A escola parecia estar entre paredes, ficar entre paredes, sem área

\footnotetext{
${ }^{6}$ A Escola Municipal de Educação Infantil Dona Leopoldina, está situada no bairro Vila Leopoldina, zona Oeste de São Paulo. Atende crianças com idade entre 4 e 5 anos apresenta ao longo de anos de luta e resistência pela escola pública, com projetos reconhecidos em todo o país pela capacidade criativa e acolhedora com que atende famílias e crianças. O projeto referido resultou de reivindicações das crianças e contou com a participação das famílias, Museu da Casa Brasileira e Secretaria Municipal de Cultura, informações sobre o projeto no site https://mcb.org.br/pt/noticias/educativo-do-mcb-inaugura-casa-da-arvore-e-observatorio-de-passaros-na-emeidona-leopoldina/. Realmente são aprendizados constantes desde o portão de entrada da escola cujo funcionamento tão concatenado às crianças revela a justa medida da participação precisa e sensível da gestora e equipes docente e de apoio.
}

7 Segue link de matéria do jornal local sobre a projeto mencionado. https://www.lavozdegalicia.es/noticia/pontevedra/pontevedra/2016/06/28/colegio-ensenaarquitectura/0003_201606P28C2991.htm 
externa e aberta acima, confinada, ou que confinavam as crianças. Elas não podiam ficar todas juntas de uma vez no pátio e eram divididas em grupos. Essa escola fica ao lado de uma praça de Pontevedra, praça que as crianças não podiam frequentar, ficava vazia, e foi separada por uma rua. Rua, praça e escola que não se entendiam, mas estavam lá. Mas as crianças não podiam sair para a praça! E queriam! E então nós depois das sessões em que trabalhamos com as crianças, fizemos um estudo de campo, sozinhas, nós adultas e com as crianças. Saímos na rua e estudamos aquela praça. Perguntávamos para as crianças: O que você sabe? O que poderia estar lá? Como é a praça? Vocês vão para lá? E então as crianças fizeram suas propostas para conectá-la à escola. Ao olhar para a praça de modo mais sensível e compreendê-la, todos a viram, algo que não viam quando passavam por lá para ir à escola. Então todos viram que a praça tinha que ser incorporada à escola e fizeram suas próprias propostas para ambas.

Marcia: O que as crianças diziam? Quais suas ideias?

Ana: Havia coisas muito imaginativas, porque elas queriam colocar parques de diversões, um zoológico para crianças, grafites. Ideias muito inusitadas e que conduziram, em parte, nosso trabalho nesse projeto. Depois aplicamos em outros tipos de projetos, também de arquitetura e educação ${ }^{8}$. Foi preciso filtrar todas essas informações e trazê-las para a realidade da cidade e dos desejos e demandas das crianças e do que era possível construir.

Nosso desafio foi filtrar todas essas informações e trazê-las para um plano que poderia ser voltado à realidade da cidade e dos desejos e necessidades das crianças.

Obviamente você não poderia fazer uma piscina enorme ou um lago, ou montar um zoológico, mas poderia criar uma conexão para trazer a praça mais perto da escola. Era importante ter pedestres na rua que separava a praça da escola, e eles não foram esquecidos, foram contemplados numa das propostas infantis em as pessoas/pedestres estavam entre seus projetos em meio a montagem de um parque de diversões, a uma montanha-russa, lá estavam as pessoas. Foi compreendido que tínhamos que fazer uma rua que ligasse a praça à escola. $\mathrm{E}$ isso partiu das crianças!

Marcia: quais suas posturas, como encaminhavam o trabalho?

\footnotetext{
${ }^{8} \mathrm{O}$ diálogo entre a arquitetura e a educação são fundamentais como pontos que podem estimular reflexões entre e com ambas as áreas. No Brasil trata-se de algo a ser conquistado, cujo caminho foi aberto pela arquiteta Mayumi de Souza Lima.
} 
África: Então, demos vazão a toda essa informação. Nosso trabalho como técnicas era orientar as crianças, sem impor nossa visão. Quero dizer, as crianças poderiam dar sua opinião porque elas eram as únicas que iam viver o espaço, nós não voltaríamos lá, não como ocupantes fixas do lugar. Então, bem, nós fizemos uma maquete, trabalhamos com elas. As crianças fizeram suas propostas e então nós, após todas as informações coletadas com as crianças, desenvolvemos o plano no nível pré-projeto, ou seja, um plano muito básico. É quase um esboço, mas, com isso, foi possível trabalhar tecnicamente para torná-lo realidade e ouvir as crianças enquanto produziam a maquete. Esse projeto chegou aos ouvidos da prefeitura e no início eles disseram que era impossível que aquela rua fosse para pedestres porque o trânsito de carros era intenso nas imediações. Considerando esse fluxo de carros, os estudos sobre essa circulação não permitiam as circulações de carros, refletiam sobre isso, mas não podiam misturar os carros com as pessoas, com as crianças e a escola, sem esquecer a praça, que nos motivou a elaboração do projeto com as crianças. Os estudos indicavam a impossibilidade de tirar todos os carros da rua e no final ficamos com um pedaço da rua para pedestres contemplando os desejos e necessidades das crianças, cujo tempo de estar no espaço público, para percorrê-lo é diferente dos adultos. Foi feito o que tinha sido proposto para mudar o significado da praça. Antes as crianças não podiam sair, os carros estavam por toda parte. Nós, ao propor que as pessoas ficassem nas ruas, percebemos que os carros já não estavam mais passando. Onde tem crianças, não tem tantos carros.

Marcia: e quanto as legislações locais?

Ana: Agora que o espaço físico permitia que as crianças estivessem do lado de fora da escola, nos deparamos com um segundo impedimento dado pelas normas educacionais, que não permitiam que as crianças saíssem por questões de segurança, não era tão imediato que as crianças pudessem sair para as ruas, mesmo sendo pedestres. Então tivemos que encaminhar um processo junto ao Governo da Galícia, para que eles pudessem revisar a legislação de forma que o centro pudesse contar com uma praça para as crianças. Eles finalmente fizeram isso e agora as crianças saem para brincar na rua. Agora elas têm um pátio ao ar livre, junto da escola.

Foi importante para as crianças. Se as crianças fizerem suas propostas para a praça e então virem que o que se materializa é o que elas precisam, o que elas pediram, elas se apropriarão do espaço e cuidarão mais dele e respeitarão umas às outras. E isso pode se estender 
a tudo no projeto da cidade. Se elas nos pedirem opinião mudamos tudo e tudo é feito adaptado às pessoas.

Marcia: E há alguma inspiração bibliográfica?

Ana: Uma inspiração bibliográfica? Não, experiências. O que vimos está sendo feito, e estava começando a ser feito tanto na Espanha quanto em outras partes do mundo.

É um pouco... ter tomado as coisas entre nossas ideias, as coisas que vimos, coisas que lemos, que talvez não fossem sobre literatura específica da arquitetura também, mas que de repente te levam a isso, incentiva a ver e ouvir melhor, mas não tem nada tão especifico.

Marcia: Conte mais sobre as formas de escutar as crianças no território.

África: Nós perguntamos a elas naquela época, (para a construção da praça com a escola) o que realmente queriam. As crianças pedem ao prefeito o que querem na cidade. Mas, a primeira coisa são aquelas ideias mirabolantes. Tem que trabalhar com as crianças para entenderem melhor o ambiente. Não?

A escola tem um programa de cursos ainda muito restrito, apertado e isso torna as atividades ainda pouco colaborativas, ainda assim, deixam uma hora livre para a gente entrar, às vezes, não é fácil e nesse caso tivemos uma acessibilidade total, depois de várias conversas com gestores e professores. Os professores nos deixaram o espaço e nos deixaram seus estudantes alunos e eles realmente não participaram diretamente, como professores, em suas aulas, não por resistência exatamente, mas por entenderem que nossa presença contemplava os desígnios das crianças e que aqueles momentos eram nossos. Mas, é importante dizer que participavam, sem se impor. Eles colaboraram, mas nós éramos responsáveis por entregar aquelas sessões teóricas e práticas e as fazermos com as crianças.

Marcia: e o processo junto a escola?

Ana. Sim, nós íamos ao centro quinzenalmente. Durante a semana em que não íamos tentávamos nos fortalecer com os estudantes, levando-os a retomar certos conceitos que tínhamos trabalhado dentro de suas disciplinas, como por exemplo, de matemática. Havia um uso cotidiano possível já que estavam medindo o tamanho dos móveis da sala de aula, porque 
eles poderiam continuar fazendo aquele trabalho na semana em que não estávamos fisicamente, usando o que aprenderam na aula de matemática para medir a cidade e, com isso, conhecê-la. E a praça para crianças foi construída. Assemelha-se a outro projeto que fizemos com o que as crianças propuseram. A escola estaria aqui nessa área. A sexta praça e aqui já são algumas. Já temos nestas as áreas de balanço, de escorregadores considerando o que as crianças estão nos orientando a ver e fazer. O que saiu dessas propostas é que foi preciso mais, principalmente, que se precisava de mais vegetação, porque é um quadrado muito duro. E aquela conexão com pedestres que é necessária? E então, aqui, no centro daquela praça, agora há um quiosque, um lugar onde eles vendiam bebidas e doces que agora está fechado e as crianças pediram para reabri-lo. Antes de criar o quiosque nesta Praça as crianças contavam histórias de que o lugar tinha fantasmas. Era um quiosque fechado, mas tinham as lembranças da venda de doces e, claro, dos doces. Isso os motivava a pedir sua reabertura. Houve uma intervenção e foram duas intervenções que a Prefeitura decidiu fazer, a partir das crianças e com elas, e nós participamos mediando isso. E o quiosque foi reaberto e os doces voltaram a cena. Mas, não é isso o que importa somente, é que a presença do quiosque aberto promove a presença das crianças e das pessoas.

Marcia: além das praças o que mais temos para pensar numa cidade das crianças ou com elas?

Ana: Transformar pátios de escola. Eles são uma prisão.

Trabalhar com as famílias. Nós estabelecemos um questionário para famílias para informar o que estão fazendo seus filhos no pátio da escola.

O melhor do pátio, o pior, o que você acha que precisa ser mudado.

E um para professores. Também conhecer a visão de que se esse arranjo do pátio produz segregação dos $\operatorname{sexos}^{9}$.

Então fazemos uma apresentação geral do porquê estamos lá, o que queremos alcançar, no qual também lhes damos referências visuais de outros pátios, pois às vezes as crianças, os pais e os professores só viram isso e não acreditam que o país possa ser melhorado, disse.

Nesse caso, a verdade, é que o diretor que nos contatou. Nos reunimos para esse projeto inicial de Barcelos, que é o projeto inicial que apresentamos para você (Marcia - entrevistadora)

\footnotetext{
${ }^{9}$ Não poderia deixar de comentar para ilustrar a importância dos estudos entre arquitetura e educação, aqui recheados pelas ciências sociais em que é fundamental a preocupação com o espaço generificado quando refletimos sobre arquitetura escolar.
} 
e a partir daí a relação foi muito boa. Levantamos a possibilidade de trabalhar neste caso. Foi realmente para uma ajuda inicial a este programa que o Colegio de Arquitectos de Galícia nos proporcionou um recurso financeiro para poder ir trabalhar nas escolas.

Ana: Essa era uma escola pública. Acho que há muitas pessoas que acham que escolas particulares são melhores que o público e fizemos algumas mudanças em diálogo com todos.

\section{Marcia: até hoje?}

África: Já se pensou mais nisso. Mas há muitas pessoas estudantes de escolas públicas, aqui temos poucas religiosas que permanecem até agora. Às vezes é uma escolha das famílias, mas em geral achamos que nas escolas públicas as pessoas são mais, mais... Os professores podem estar mais preparados porque todos em uma escola pública têm que formar-se, e bem. O ruim das escolas públicas é que elas ainda não têm recursos para essas mudanças porque dependem da administração e temos que negociar muito. Então eles têm dificuldade em levantar dinheiro para fazer algumas coisas. $\mathrm{Na}$ Espanha, com a crise econômica, houve muitos cortes e alguns projetos cortados, especialmente na educação e na saúde. Então os centros públicos não têm muito dinheiro, e eles não podem se dar ao luxo de pedir às famílias para dar dinheiro para isso, porque uma escola pública vai para pessoas de condições nem sempre favoráveis. Talvez para alguém, 10 (dez) euros não seja nada, mas para outros é muito.

África: Fizemos um projeto com a Educação infantil. E aqui está um resumo das ações que fizemos no Infantil.

Marcia: Ana e África mostram muitos cadernos de registros.

Ana: Houve mais sessões teóricas para falar sobre temas arquitetônicos e depois sair para trabalhar aqui, bem como para vivenciar o espaço e para as crianças conhecerem o espaço de forma diferente.

África: Aprendemos que são necessárias metodologias diferentes com as crianças. As crianças são muito pequenas. Na verdade, isso foi feito com os pequenos. É um pátio cercado e então nós as fizemos refletir coisas das crianças sobre esta cerca. 
Por que as crianças têm que viver com cercas? A ação foi muito simples. Nós sempre trabalhamos com elementos muito simples. Havia alguns chocalhos pendurados nos guizos que soam na cerca de modo que de repente faz um som duro, cinza, escuro, tornou-se uma coisa que misturou cor e som e que estimula as crianças e o espaço de alguma forma. É uma coisa simples, mas tem as crianças e suas necessidades como ponto de partida.

Ana: Também fizemos ocupação de pátio na escola. Queríamos ver pátio com as crianças, ou que elas revissem o pátio. Ver o quanto ocupamos, se todos sentamos juntos ou nos separamos, o que o pátio permite e promove das relações entre todos.

No segundo ano (que corresponde ao segundo do ensino fundamental) pedimos para as crianças que fizessem sinais desenhados indicando o que mais gostariam que aparecesse no pátio. Como outra prática proposta as crianças ocuparam o espaço da escola com bolas, como queriam. A questão, em todos os anos, com as crianças estudantes, é perceber a mudança do espaço e que ele pode mudar a partir de intervenções ou propostas. Essa atividade acabou como uma grande teia de aranha, porque também usaram lãs, além das bolas. Isso tudo lhes serviu como um novo elemento de jogo, mas não só, é bom reforçar que são propostas para cultivar a percepção do espaço, aprender a percebê-lo. Após essas atividades práticas fizemos um retrato, com todos, e pedimos para colocá-lo no pátio, nos lugares que preferissem. Isso foi bom, pois levava a compreensão e apropriação desse espaço pelas crianças. É bom incentivar outro jeito de olhar.

Isso também nos deu pistas de como eles se relacionavam e juntos, separados do sol, à sombra. A ideia é criar com eles formas que permitam questionar onde estão, pois, para pensar em modificar a cidade, a escola é preciso ter prática de vê-la, antes sentir e depois projetar.

Ana: Muda o espaço e o recria. Por exemplo: quando queriam plantar árvores. Onde eles queriam aquelas árvores e por quê? Bem, nós as pintamos no chão. E isso foi mais importante como começo com essas crianças, com as mais velhas fizeram um avião, uma rota traçada. Os passeios que faziam pelo pátio, os caminhos que faziam os lugares onde paravam, isso é importante.

África: Ao longo do que vou chamar de processo perceptivo, algumas propostas aconteciam de modo concomitante, o processo foi produtor das propostas e as acolheu de algum modo. Crianças saiam do pátio da escola com outras crianças, em conversas e isso é criativo. E 
estas são algumas propostas que saiam deles e que informavam o que elas queriam para o seu pátio:

- Colchões, camas elásticas;

- Slides;

- As Fontes do Labirinto;

- Um lugar com árvores e uma mesa;

- Mais labirintos;

- O parque de diversões. O parque de diversões é muito recorrente;

- A casa da árvore. Mas bem, áreas verdes já estão aparecendo aqui.

E então, com tudo isso elencado uma assembleia geral foi realizada com um representante adulto de cada curso, para trabalhar esses temas considerando as propostas das crianças: os pavimentos, bancos, decks, acessos, brincadeiras, jogos de bola, área infantil, vegetação e balanços.

África: Depois, claro, estávamos trabalhando um dia com as crianças do Infantil, outro com os primeiros, com os segundos, outro com os terceiros anos. Então, com esta última reunião o que estávamos procurando é que todos se comunicassem com um porta-voz em cada nível o que queriam para que todos fossem informados de tudo o que foi feito. Havia uma percepção de escola sem tantas diferenças etárias, sem tantos compartimentos, que partia das crianças quando provocadas a dizer.

Então eles trouxeram uma lista de intenções de cada um de seus grupos e apresentaram para todos que estavam presentes. E para organizar um pouco, lidamos com as questões apresentadas. Primeiro falamos sobre o piso do pátio e não queriam piso de grama. Eu geralmente tenho dificuldade, porque se precisamos de árvores, precisamos de sombras. E assim foi com os pequenos e eles foram apoiados por seus professores, para discutir sobre as árvores. As crianças pequenas faziam coisas sozinhas, falavam sem um porta-voz. Falavam bastante e, às vezes, algumas coisas engraçadas. Aprendemos que com elas é bem assim, menos conversa e mais ação com as crianças bem pequenas.

África: As crianças expressaram suas conclusões através de desenhos e com a ajuda dos professores também. Então eles nos disseram o que tinham falado com as crianças todo esse 
tempo. Elas comentaram e fizeram inferências com os desenhos produzidos ao longo do processo de discussão e pensamento projetivo sobre o espaço. O desenho foi um aliado nisso. Se você falar, fale com as crianças, elas explicam como se relacionar com desenhos com os desenhos delas, nós não sabemos lidar com os desenhos criados por elas, porque lidamos com nossos desenhos, somos arquitetas, adultas. Sabemos de desenhos de adultas.

Bem, sim, estamos lá. Perguntamos muito: sobre o que está sendo desenhado? Perguntamos, porque às vezes não entendemos tudo. Num dos desenhos apareceu uma piscina, e as crianças apontavam o papel desenhado e diziam "aqui vai ser outra coisa". E a mim, parece sempre estranho, pois muitas vezes não entendo desses traços, desses desenhos. Vou aprendendo.

Quando não conseguimos, pedimos aos professores para pegar os desenhos. Pedimos que escrevam para nós atrás para informar sobre como fizeram. Quais são as intenções no desenho? Muitas vezes eles falam sozinhos, mas outras vezes é necessário perguntar, escrever atrás para lembrar e dar continuidade ao projeto.

Ana: Este projeto do qual estou falando aqui de refletir sobre os pátios está nesse estado agora, ainda não finalizado. Esse é o estado atual e estamos com toda essa informação para fazer alterações no espaço, a partir do que as crianças estão nos dizendo e falando.

África: Como dissemos, é um processo. Fazemos síntese em um nível preliminar de projeto com as crianças, com nossas observações. Elas podem então ser trazidas à realidade, neste caso a intervenção. Então os membros da escola têm que conversar com seu gestor, para ver se ia fazer alguma das transformações. O que ainda falta é a comunicação com as autoridades. Ao final, como eu disse, as escolas dependem do dinheiro público e são os municípios que podem dizer, ou a Junta Municipal, o Governo da Galícia, que podem decidir se fazem essas transformações nas escolas, nas praças, a partir do que as crianças estão projetando conosco.

Ana: Falando de alguns outros projetos com as crianças e que mudam a relação com a cidade, como você queria entender, criamos uma área de pomar que também foi solicitada pelas crianças e tirolesa, em outra escola.

E bem, estávamos procurando espaços que não interrompessem muito a operação do pátio, porque no final você precisa de um perímetro de segurança. Nossa proposta, e que no 
final foi conquistada, nós mantivemos areia no pátio e removemos a cerca, o que para nós, foi uma grande conquista. A cerca na escola era horrível e as crianças não têm que ficar dentro de cercas que ficam dentro das escolas...

Não entendemos por que há regulamentações tão rigorosas para as crianças mais novas hoje. São muito rigorosas e as normas do Ministério da Educação, ou seja, aquela que fala sobre como devem ser os pátios quando as crianças saem ao mesmo tempo. Crianças de diferentes idades, ou seja, as de 3, 4 e 5 anos e as de 6 a 12 anos, ficam no mesmo espaço do pátio. A regra diz que eles têm que estar separados e a maneira de separá-los é com uma cerca e é como uma espécie de gaiola para os pequenos. Mas como compartilham espaço e tempo, por que devem ser separados? Não se pensou em outra maneira além de uma cerca?

Ana: A tirolesa e aquela área infantil que sempre estava lá como isolada, porque a colocamos no centro do pátio e conectadas às suas saídas. É onde fica a área das crianças. Nós gostamos das soluções de Van Eyck ${ }^{10}$ e sabemos disso que com uma barra simples, com materiais simples que têm melhor resultado do que as coisas mais complicadas que são colocadas nos parques.

África: E também outra coisa muito requisitada, além da tirolesa, é o skate para poder andar em diferentes áreas de um determinado e interromper todo o espaço. Por que não? Por que não permitir a conexão entre diferentes lugares?

Esta foi uma outra experiência.

Ana: Por exemplo, o prefeito tem demonstrado sua vontade de fazer essa transformação, ou seja, o prefeito depois desse trabalho, que é um trabalho teórico e torna-se prático. Ainda são intenções, é preciso trazê-lo à realidade e nessa cidade, onde as crianças criam desenhos como aqueles que acabamos de te mostrar, o prefeito quer fazer essa mudança porque o centro da cidade é um centro muito grande que muitas pessoas da área vão e parece um núcleo importante da comunidade e que temos que transformá-lo, tem que ser melhorado. Então ele quer fazer a transformação, inclusive incorporando novos espaços nas escolas em relação com a cidade, com o centro.

África: Nesse momento a Câmara Municipal de Pontevedra está interessada no modelo de cidade para crianças, de pedestres e que não há carros, que chega às escolas de alguma forma,

${ }^{10}$ Ana referia-se ao arquiteto holandês Aldo Van Eyck. 
mas não sabem muito bem como fazer. Então o Conselho da Cidade concorda e fazemos esses projetos com as crianças.

Ana: Alguns desses são os que nós o chamamos de cidade na sala de aula, um deles começamos com uma ação surpresa, parece estranho, mas vamos encontrando alguns elementos que possam suscitar descobertas. Encontramos algumas caixas na sala de aula e o que as crianças estavam fazendo com aquelas caixas? Claro, vamos lá, era uma festa.

Eles brincaram com elas. Muito interessante essa experiência. Entramos em uma caixa quando entramos. Isso é pouco? Parece pouco, mas foi uma investigação de dentro para fora. Primeiro como espaço, depois na escola e depois na cidade. Eu estava indo de dentro para fora. Isso foi muito experimental porque elas são crianças muito pequenas.

E depois? Bem, isso, um pouco o que ocupamos primeiro dentro de uma caixa, em uma caixa pequena, não entramos um pouco maior se no próximo já entramos em três módulos que depois ocupamos também com fitas no chão, de um quadrado menor para um maior. Quantos de nós entramos? Isso é um exercício para perceber o espaço, para planejar, sentir. São experimentos. Foi tudo com muito experimento e conversa. Depois e durante isso fazíamos perguntas, observávamos, participávamos. O que você sentiu que achou confortável e desconfortável porque trabalhamos com nossas sombras. Nós desenhamos um ao outro. Um desenho de Bashir ${ }^{11}$. Um estava de pé e o outro estava desenhando. E aqui entramos em mais elementos da cidade com um papelão que fizemos uma parte da rua.

África: E vamos elaborando perguntas provocadas pelo que vemos e fazemos com as crianças no espaço. E o que queremos nessas calçadas? Para que usamos a rua? Queremos andar de bicicleta? Nós queremos andar. Nós queremos ir quadra. Queremos árvores. Nós queremos isso. Cada um estava incorporando o elemento que queria, que achava importante.

Mostramos a eles um exemplo que também nos surpreendeu o quão bem crianças de quatro anos foram trazidas para a casa, o contexto e as condições da casa. O quarto, curiosamente, aparecia, e mostravam o que cada um gostava mais. As crianças queriam desenhar o que lembravam de suas casas.

Este foi um pouco de um exercício de síntese, em que estavam presentes a família, colegas de classe, os colegas da vizinhança. Como toda vez, o círculo era maior. Se eu tivesse cinco irmãos, parentes, colegas de escola.

${ }^{11}$ Ana referia-se a uma forma de desenho de memória. 
Sempre introduzimos alguma atividade de expressão plástica, algo também de arte e atividades, embora estejamos falando de arquitetura, é sempre uma atividade plástica e lúdica ao mesmo tempo.

E então construímos a cidade, cada uma com sua caixa, prédios diferentes e essa atividade que retomamos este ano. Para fazer isso, criamos um último projeto que podemos te dizer. Demos a eles algumas câmeras fotográficas de uso e lançamento e demos uma volta pela cidade e que cada criança pegasse o que chamou sua atenção.

E coisas lindas saíram.

A verdade é que uma nova cidade foi construída e acabamos com um trabalho muito bom que era a relação com a escola de formação do professor e que as crianças também aprenderam essas crianças que enquanto elas estão fazendo as coisas, outros também estão passando por outras coisas, em outro lugar.

Ana: Hoje, terminamos uma exposição que tivemos aqui na cidade. Um concurso de fotografias tiradas pelas crianças em que deviam mostrar a cidade de Pontevedra. Propusemos à Câmara Municipal que, aproveitando todo esse tema do modelo da cidade para pedestres, fizemos um programa em que havia um concurso de fotografia para adultos e outro para crianças em que retratassem as crianças desfrutando dos espaços da cidade. E então, por outro lado, havia alguns. Fizemos algumas oficinas de fotografia, não em oficinas de fotografia realmente, porque o objetivo não era ensinar a fotografar, era ser pouco flaneur, andar pela cidade e para as crianças tirarem fotos do que mais chamava a atenção. Então nós montamos três rotas através de Pontevedra, através da área antiga. Eu não sei se você foi dar uma volta e viu. Sim, sim, porque fizemos algumas rotas através de Pontevedra, através dos lugares que mais ou menos costumam visitar quando alguém vem de fora. A coisa mais bonita, digamos, não vai onde eu moro, é muito mais longe e não há nada interessante.

África: Foram três fotos vencedoras da exposição você viu?

Marcia: Sim, logo que cheguei à cidade, na entrada da região central.

Assim terminou nossa conversa entre as rememorações de minha chegada à cidade de Pontevedra, em que, de fato, encontrei uma exposição de fotos com crianças e feitas por crianças que fotografavam enquanto deambulavam pela cidade, registrando-a. Importa chamar 
a atenção que se tratou de uma riquíssima conversa da qual extrai alguns momentos que emprestam e instigam pensamentos ao leitor, ou à leitora: a valiosa relação entre arquitetura e cidade; as cidades compreendidas a partir dos pontos de vista das crianças; as relações entre a comunidade e as crianças; a importância de garantirmos a presença dos pedestres, entre tantas outras que se pauta no respeito às crianças em sua forma mais profunda. Vale ressaltar que são propostas e práticas existentes em outro continente, num país com características bastante diferentes das nossas. Não poderia deixar de lado uma observação que certamente já foi considerada por algumas leitoras ou leitores, qual seja, as conversas ocorreram com um grupo de mulheres que compõem um coletivo. Atentas para as mudanças e junto com as crianças provocando processos inventivos na relação com a cidade. Sai, refletindo que, talvez, tenhamos chegado num ponto zero, nas palavras de Silvia Federici ${ }^{12}$, em que as perdas de possibilidades na e da vida, em que vigoram desejos subsumidos numa vida programada e vazia de sentidos, podem levar à invenção de modos não desiguais de existência, e já estão levando e cumprindo esse percurso. Certamente é um caminho que aponta para outros. Mas, quero sublinhar que, fundamentalmente, houve apenas um grande motivo que levou à apresentação dessa conversaentrevista: refletir sobre a importância de pensar as cidades com as crianças de todas as idades. Considerar seus pontos de vista como paradigmas é imprescindível quando queremos e lutamos por transformações sociais. Mas, reforço a necessidade de considerarmos todas as perspectivas. Olhar com as crianças implica considerar todas elas, desde bebês, e que todas sejam vistas, sentidas, escutadas. Negras, indígenas de todas as etnias, brancas, em situação de rua, sem teto, com teto, enfim... que todas tenham suas vozes e pontos de vistas considerados para pensarmos juntos sobre outras cidades e relações.

\section{SOBRE A AUTORA:}

\section{Marcia Aparecida Gobbi}

Possui Doutorado em Educação pela Universidade Estadual de Campinas. Professora da Faculdade de Educação da Universidade de São Paulo, atuando nos cursos de Licenciatura em Ciências Sociais e de Pedagogia e junto ao Programa de Pós-Graduação em Educação. Atualmente dedica-se a investigar representações e criações da infância em luta por moradia em ocupações na cidade de São Paulo. Coordenadora do Grupo de Estudos e Pesquisas "Crianças, práticas urbanas, gênero e imagens" (CNPq/FE/USP). E-mail: mgobbi@ @usp.br iD http//orcid.org/0000-0001-9850-01901

12 FEDERICI, Silva. O ponto zero da revolução: trabalho doméstico, reprodução e luta feminista. São Paulo: Editora Elefante, 2019. 


\section{$\underline{\text { REVISÃO TÉCNICA }}$}

\section{Cleriston Izidro dos Anjos}

Possui Doutorado em Educação pela Universidade Federal de Alagoas. Professor do Centro de Educação da Universidade Federal de Alagoas, Membro do Corpo Docente do Mestrado em Educação Pré-Escolar da Universidade Katyavala Bwila (Angola), Membro Colaborador Doutorado do Centro de Investigação em Estudos da Criança da Universidade do Minho (Portugal) no grupo "Contextos, quotidianos e bem estar da criança". Atua principalmente nos seguintes temas: Educação Infantil, Formação Docente, Linguagens Expressivas e Culturas das Infâncias. Coordenador do GEPPECI - Grupo de Estudos e Pesquisas em Pedagogias e Culturas Infantis (CNPq/CEDU/UFAL). E-mail: cianjos@yahoo.com.br

(iD http://orcid.org/0000-0003-1040-4909

\section{Juliana Diamente Pito}

Possui Mestrado em Educação pela Pontifícia Universidade Católica de São Paulo e é estudante de doutorado pela Faculdade de Educação da Universidade de São Paulo. Atua como professora da Escola Paulistinha de Educação - UNIFESP. E-mail: jdiamente @ hotmail.com

iD http://orcid.org/0000-0003-0850-4249

\section{Paula Martins Vicente}

Possui Mestrado em Arquitetura e Urbanismo pela Faculdade de Arquitetura e Urbanismo da Universidade de São Paulo (FAU/USP). Pesquisa a relação das crianças com os espaços livres públicos da cidade, com enfoque nas áreas periféricas. É pesquisadora junto ao Laboratório Paisagem, Arte e Cultura (LABPARC/FAU/USP) e do grupo de Estudos e Pesquisas "Crianças, práticas urbanas, gênero e imagens" (CNPq/FE/USP). E-mail: paulamv.arq@ gmail.com (iD http://orcid.org/0000-0002-7768-598X, 